\title{
Qualidade da água de granjas de postura comercial da região Sul de Santa Catarina em relação ao Ofício Circular Conjunto DFIP/DSA no $1 / 2008$
}

\author{
Water quality of commercial laying hen farms in the southern region of Santa \\ Catarina regarding the report DFIP/DSA 1/2008
}

\author{
Natály Ramos Cardozo ${ }^{*}$, Vinícius Rodrigues da Silva', Juliana Dias Siqueira², André Thaler Neto, \\ Luiz Cláudio Miletti ${ }^{3}$, Clóvis Eliseu Gewehr ${ }^{3}$
}

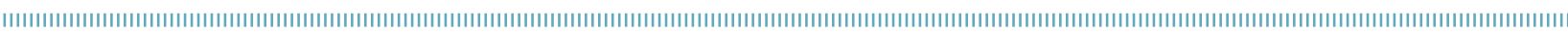

\begin{abstract}
RESUMO: O objetivo deste trabalho foi avaliar a qualidade da água de granjas de postura comercial da região Sul de Santa Catarina e contextualizá-la com o Ofício Circular Conjunto DFIP/DSA $n^{\circ} 1 / 2008$. Em fevereiro de 2012 foram coletadas amostras de água de 31 granjas localizadas nos municípios de São Ludgero, Orleans, Grão Pará e Braço Norte. Os parâmetros químicos e microbiológicos avaliados foram os estabelecidos no anexo II do Oficio Circular Conjunto DFIP/DSA n ${ }^{\circ} 1 / 2008$. Sendo assim foram analisados cloreto, dureza, nitrato, sulfato, $\mathrm{pH}$ e sólidos dissolvidos totais (SDT) e Escherichia coli no que se refere à análise bacteriológica. Quantificou-se a adequação das amostras em relaçáo ao Ofício Circular Conjunto DFIP/DSA no $1 / 2008$ e avaliou-se a qualidade da água de acordo com o tipo de fonte e número de aves em produção por meio da análise de variância. Os resultados indicaram que as águas apresentaram adequação para SDT, cloreto e sulfato. Foi encontrada inadequação nos parâmetros: $\mathrm{pH}$ (em $26 \%$ das amostras), dureza (6,5\%), nitrato (54,8\%) e presença de Escherichia coli $(46,2 \%)$. As análises de acordo com o número de aves e tipo de fonte não apresentaram diferença estatística significativa $(\mathrm{p}>0,05)$. Observaram-se que $93,5 \%$ das amostras não se enquadraram em pelo menos um parâmetro. Concluíram-se que as águas das granjas da Região Sul de SC não estão totalmente de acordo com o Ofício Circular Conjunto DFIP/DSA no $1 / 2008$, apresentando problemas no que se refere ao $\mathrm{pH}$, dureza, nitrato e E. coli; a qualidade da água independe do número de aves em produçấo e do tipo de fonte que abastece a granja.
\end{abstract}

PALAVRAS-CHAVE: avicultura; Escherichia coli; fontes de água; galinhas; poedeiras.

\begin{abstract}
The aim of this study was to evaluate the water quality of laying hen farms in the South of Santa Catarina and contextualize them with the report DFIP/ DSA 1/2008. Water samples were collected in February, 2012, from 31 farms located in the cities of Sáo Ludgero, Orleans, Grão Para and Braço Norte. The chemical and microbiological parameters were set out in Attachment II, in the report DFIP/DSA 1/2008. Thus, the following were analyzed: chloride, hardness, nitrate, sulfate, $\mathrm{pH}$ and total dissolved solids (TDS) and Escherichia coli regarding the bacteriological analysis. The suitable samples were quantified for the report DFIP/DSA $1 / 2008$ and water quality was evaluated according to the font type and number of birds in production by analysis of variance. The results indicated that water presented suitability to SDT, chloride and sulfate. Inadequacy was found in $\mathrm{pH}$ (in $26 \%$ of samples), hardness (6.5\%), nitrate (54.8\%) and the presence of Escherichia coli (46.2\%). The analysis according to the number of birds and font type showed no statistically significant differences $(p>0.05)$. It was observed that $93.5 \%$ of the samples did not fit in at least one criterion. It is concluded that the waters from farms in the southern region of SC are not fully in accordance with the report DFIP/DSA 1/2008, presenting problems with regard to $\mathrm{pH}$, hardness, nitrate and E. coli; the water quality is independent of the number of birds in production and type of source that supplies the farm.
\end{abstract}

KEYWORDS: poultry production; Escherichia coli; water sources; hens; layers.

\footnotetext{
'Departamento de Biomedicina; Universidade do Planalto Catarinense (UNIPLAC) - Lages (SC), Brasil.

${ }^{2}$ Curso de Biomedicina; UNIPLAC - Lages (SC), Brasil.

${ }^{3}$ Departamento de Produção Animal e Alimentos; Universidade do Estado de Santa Catarina (CAV/ UDESC) - Lages (SC), Brasil.

*Autor correspondente: natalycardozo@hotmail.com

Recebido em: 04/07/2013. Aceito em: 26/11/2014
} 


\section{INTRODUÇÃO}

A água é fundamental para todos os procesos biológicos. Depois do oxigênio, é o nutriente mais importante para os seres vivos. Ao enfocar o termo sustentabilidade ambiental, a água sempre ganha destaque, pois sabe-se de sua importância para a manutenção da vida. Embora sua extrema importância seja conhecida, segundo Thulin; Brumm (1991) a água já foi designada como o "nutriente esquecido". Neste contexto, torna-se interessante conhecer a qualidade da água utilizada nos diferentes processos produtivos.

Para a dessedentação das aves, o uso de água de qualidade química ou bacteriológica duvidosa pode afetar os índices zootécnicos (TABLER, 2003). Quando utilizada na dessedentação das aves, visto que todos os animais têm acesso à mesma fonte, o uso de água de qualidade duvidosa interfere no bem-estar, nos índices zootécnicos e na disseminação de enfermidades, acarretando graves prejuízos econômicos, além de carrear agentes patogênicos de doenças de interesse em saúde pública (Soares; Mesa, 2009).

Há algum tempo, padrôes para atestar a qualidade que a água deve ter para ser utilizada vêm sendo discutidos, seja para uso humano ou animal. Regularmente as resoluçôes sofrem modificaçôes, pois à medida que novos indicadores surgem existe a necessidade de adequaçóes. Em 2007 foi criada a Instrução Normativa 56, do Ministério da Agricultura, complementada pelo Ofício Circular Conjunto DFIP/DSA $n^{\circ} 1 / 2008$, o qual estabelece padróes para a qualidade da água a ser fornecida às aves nos estabelecimentos avícolas. $\mathrm{O}$ anexo II deste Ofício Circular indica sete parâmetros com níveis adequados para avaliar a qualidade da água oferecida às aves: sólidos dissolvidos totais ( $\mathrm{SDT}), \mathrm{pH}$, dureza total, cloretos, nitrato, sulfato e Escherichia coli. Existe, portanto, uma legislação, mas raros são os trabalhos científicos publicados que refletem a realidade observada nas granjas de postura comercial, e que possam servir de parâmetros a serem aplicados em outras regióes.

A regiáo Sul de Santa Catarina concentra grande parte dos produtores de ovos do Estado (GeweHr et al., 2010). Estima-se que nesta região estejam alojadas aproximadamente 1 milhão de aves de postura comercial, o que corresponde a $60 \%$ do plantel total de poedeiras de Santa Catarina. Os produtores são todos independentes, de pequeno e médio porte, ou seja, não estáo vinculados a uma agroindústria, sendo detentores dos meios de produçáo. Isso pode evidenciar uma dificuldade para que estes produtores saibam qual é a real situação da qualidade da água que usam para abastecer as granjas, bem como a legislação vigente.

Com base no exposto, o objetivo deste trabalho foi analisar a qualidade da água de granjas da regiāo Sul de Santa Catarina observando a adequação aos parâmetros estabelecidos pelo Ofício Circular Conjunto DFIP/DSA no 1/2008, do Ministério da Agricultura, em relaçáo ao número total de granjas, a quantidade de aves criadas em cada granja e a origem da água que as abastece.

\section{MATERIAL E MÉTODOS}

Foram coletadas amostras de água de torneiras localizadas no final das linhas que abastecem os bebedouros dos galpóes de 31 granjas de aves de postura comercial, na regiáo Sul de Santa Catarina, em fevereiro de 2012. As amostras de água foram coletadas em um único dia, sendo as visitas previamente agendadas com os produtores.

Antes da coleta as torneiras foram higienizadas com algodão embebido em álcool $70 \%$. Em seguida, as torneiras foram abertas e a água escorreu durante 2 minutos. Então, a amostra de água foi colhida em frascos de vidro de tampa rosca previamente autoclavados, tomando-se todos os cuidados para que o processo ocorresse de maneira asséptica. Após a coleta, os frascos com as amostras de água foram colocados em caixas isotérmicas $\left(2\right.$ a $\left.8^{\circ} \mathrm{C}\right)$, que foram transportadas imediatamente para o laboratório onde realizaram-se as análises.

No tocante à qualidade química em relação ao Ofício Circular Conjunto DFIP/DSA no $1 / 2008$, foram realizadas as análises de sólidos dissolvidos totais (SDT), $\mathrm{pH}$, dureza total, cloretos, nitrato e sulfato. Análises de $\mathrm{pH}$ e de sólidos dissolvidos totais foram feitas por meio de aparelho condutivímetro, da marca Homis, com faixa de mediçấo 0 999 ppm e $0-14 \mathrm{pH}$.

A dureza total foi medida pelo método de titulação colorimétrica, cujo procedimento de análise foi realizado separando $10 \mathrm{~mL}$ da amostra de água em um tubo de ensaio. Logo após houve a adiçáo de $0,20 \mathrm{~mL}$ de solução de hidróxido de amônio, agitando-se em movimentos circulares. Em seguida foi adicionado $0,05 \mathrm{~g}$ de Negro de Eriocromo T, agitando novamente até a amostra adquirir a coloraçấo rosa. Adicionaram-se em uma bureta $2 \mathrm{~mL}$ de solução EDTA e, em seguida, gotejou-se o reagente da bureta na amostra (titular) agitando sempre a cada gota adicionada, até a cor azul pura ser atingida. Quando isso ocorreu o resultado foi lido pelo reagente gasto na escala da bureta em $\mathrm{mg} / \mathrm{LCaCO}_{3}$.

Para análise de cloretos utilizou-se o método de titulação colorimétrica, no qual $10 \mathrm{~mL}$ da amostra de água foram separados em um tubo de ensaio, adicionando-se $0,10 \mathrm{~mL}$ do cromato de potássio. Em seguida, foram feitos movimentos circulares. Usando uma bureta com $2 \mathrm{~mL}$ de nitrato de prata gotejou-se o nitrato de prata na amostra (titular), agitando a cada gota até a mudança de cor de amarelo para amarelo tijolo. $\mathrm{O}$ resultado foi lido pelo volume de reagente gasto na escala da bureta em $\mathrm{mg} / \mathrm{L}$ de $\mathrm{Cl}^{-}$. 
O método de titulação colorimétrica também foi utilizado para analisar o nitrato, no qual $5 \mathrm{~mL}$ da amostra de água foram transferidos para uma cubeta, adicionando $0,05 \mathrm{~g}$ do biftalato de potássio/zinco $7 \%$, agitando até dissolver. Logo após adicionou-se $0,05 \mathrm{~g}$ do N-(1-N-Naftil) Etilenodiamino Bicloridrato e agitando até dissolver novamente. Depois, foi adicionado $0,10 \mathrm{~mL}$ de ácido clorídrico $15 \%$, agitando-se e aguardando 15 minutos. Logo em seguida a amostra foi posicionada sobre uma cartela de cor, procedendo-se à comparação da cor. Faixa de leitura: $0,10-2,50 \mathrm{mg} / \mathrm{L} \mathrm{N}-\mathrm{NO}_{3}$.

A análise de sulfato foi realizada pelo método de titulação colorimétrica, pelo qual $5 \mathrm{~mL}$ de água deionizada foram medidos com uma proveta, transferindo-se para um tubo de vidro. Em outro tubo de vidro foram medidos $5 \mathrm{~mL}$ de amostra, adicionando-se $0,5 \mathrm{~mL}$ de cloreto de sódio, procedendo ao agitamento. Em seguida, adicionou-se 0,05 g de cloreto de bário e, por 5 minutos, a amostra foi agitada intensamente. A leitura na cartela foi realizada da seguinte maneira: posicionou-se o tubo com água deionizada sobre cada círculo de cor e o tubo com amostra ao lado, sobre o fundo preto da cartela, até encontrar a cor coincidente. Faixa de leitura: 5,0 - 50,0 mg/ $\mathrm{L} \mathrm{SO}_{4}$.

Para a análise microbiológica foi utilizada a Técnica dos Tubos Múltiplos, também chamada de Técnica do Número Mais Provável (NMP), utilizando três séries de três tubos, contendo caldo lactose duplo na primeira série e caldo lactose simples na segunda e terceira séries. Após incubação por 48 horas a $37^{\circ} \mathrm{C}$, todos os tubos com produção de gás foram separados e repicados para o caldo verde brilhante e caldo EC. Os tubos positivos em cada série foram interpretados em tabela padrão NMP e originaram, com intervalo de confiança de $95 \%$, o número mais provável de micro-organismos presente em $100 \mathrm{~mL}$ de água (DA SiLva et al., 2005).

Os resultados das amostras foram comparados com os padróes estabelecidos no Ofício Circular Conjunto DFIP/ DSA n ${ }^{\circ} 1 / 2008$, fazendo-se uma análise descritiva dos resultados. Os dados referentes às concentraçôes de $\mathrm{pH}$, cloreto e sulfato foram submetidos à análise de variância utilizando a ferramenta GLM do pacote estatístico SAS (Sas_Institute, 1999).

Foram avaliados os efeitos do número de aves em produção (granjas com até 20 mil aves e acima de 20 mil aves) e da origem das águas que abastecem as granjas (vertente e poço). Os dados foram previamente testados para a normalidade dos resíduos através do Teste de Shapiro-Wilk.

A influência da fonte e do número de aves sobre a conformidade em relação ao Ofício Circular Conjunto DFIP/DSA $n^{\circ} 1 / 2008$ para as variáveis em que não ocorreu não conformidade $(\mathrm{pH}$, dureza, nitrato e $E$. coli) foram avaliados pelo teste qui-quadrado, utilizando o procedimento FREQ do pacote estatístico SAS.

\section{RESULTADOS E DISCUSSÃO}

As análises foram baseadas no Ofício Circular Conjunto DFIP/DSA no 1/2008, que complementa a Instrução Normativa 56/MAPA, de 2007, legislação em vigência quando ocorreu a análise das amostras. No entanto, no dia 7 de dezembro de 2012, o Ministério da Agricultura (MAPA) publicou a Instruçáo Normativa no 36 , que passou a ser referência desde entáo.

A origem da água de granjas de postura em Santa Catarina é: $47,0 \%$ provenientes de poços artesianos; $23,5 \%$, de rios; apenas 6,0\%, da Companhia Estadual de Santa Catarina (CASAN); e outros $17 \%$ são provenientes de mais de uma fonte (GeweHr et al, 2010). Neste aspecto, evidencia-se que no mínimo $70,5 \%$ da água que abastece as granjas de Santa Catarina dependem da açáo do produtor para ser tratada.

$\mathrm{Na}$ análise de SDT, todas as amostras analisadas encontraram-se adequadas às exigências da legislação (Tabela 1). Do total de amostras analisadas, $62,2 \%$ se encontraram na faixa de $51-100 \mathrm{ppm}$. Esta análise é realizada por meio da quantificação de todas as impurezas dissolvidas, com exceçâao de gases. Cálcio, magnésio, sódio, cloro, bicarbonato e enxofre são minerais que contribuem para a determinação do nível de SDT (Penz Júnior, 2002; MACÊDo, 2007). A análise de SDT é um parâmetro importante a ser monitorado em se tratando de qualidade da água na produção avícola, pois à medida em que o seu valor aumenta, a qualidade piora, o que faz diminuir o consumo de água pelas aves (NRC, 1974).

Em relação aos resultados da análise de $\mathrm{pH}$, do total de amostras coletadas, $26 \%$ apresentaram-se inadequadas (Tabela 1). Todas as amostras inadequadas apresentaram $\mathrm{pH}$ abaixo de 6, o que representa um problema, pois quando o pH está alterado pode ocorrer alteração no desempenho, na performance dos lotes, na produçáo e na qualidade dos ovos.

No parâmetro dureza, apenas $6,5 \%$ do total de amostras apresentaram-se inadequadas, ou seja, apresentaram índices maiores que $110 \mathrm{mg} / \mathrm{L}$ (Tabela 1 ).

Tabela 1. Qualidade da água de granjas de postura comercial da região Sul de Santa Catarina em adequação aos padrões indicados pelo Ofício Circular Conjunto DFIP/DSA n 1/2008.

\begin{tabular}{lccc} 
Parâmetro & $\begin{array}{c}\text { Padrões de } \\
\text { Referência }\end{array}$ & $\begin{array}{c}\text { Inadequadas } \\
(\%)\end{array}$ & $\begin{array}{c}\text { Adequadas } \\
(\%)\end{array}$ \\
\hline SDT & $<500 \mathrm{mg} / \mathrm{L}$ & 0,0 & 100,0 \\
\hline $\mathrm{pH}$ & $6-9$ & 26,0 & 74,0 \\
\hline Dureza & $<110 \mathrm{mg} / \mathrm{L}$ & 6,4 & 93,6 \\
\hline Cloreto & $<250 \mathrm{mg} / \mathrm{L}$ & 0,0 & 100,0 \\
\hline Nitrato & $<10 \mathrm{mg} / \mathrm{L}$ & 54,8 & 45,2 \\
\hline Sulfato & $<250 \mathrm{mg} / \mathrm{L}$ & 0,0 & 100,0 \\
\hline E. coli & $\mathrm{O} / 100 \mathrm{~mL}$ & 45,2 & 54,8
\end{tabular}


$\mathrm{Na}$ análise de $\mathrm{pH}$, de acordo com o número de aves, os resultados indicaram que $26,7 \%$ das amostras apresentaram-se inadequadas (Tabela 2), e aquelas que tinham como origem a água de poço apresentaram-se com 30,4\% de inadequação, sendo que as granjas abastecidas com água de vertente tiveram $12,5 \%$ de inadequação (Tabela 3). Um pH alterado pode precipitar antibióticos, prejudicar a eficácia da cloração da água, comprometer a ação das vacinas vivas, além de prejudicar a ação de desinfetantes (Block, 1991; Figueiredo, 1999). Especificamente, a água ácida pode causar problemas para o produtor, como diminuição do desempenho das aves, prejudicando a lucratividade. No entanto, a literatura apresenta resultados controversos sobre esta questão.

LAURentiz et al. (2001) observaram que aves que receberam água com $\mathrm{pH}$ 4,8 não apresentaram alteração no desempenho nem no consumo de água. Entretanto, Carter; Sneed (1996) observaram redução no desempenho das aves quando elas receberam água com valor de $\mathrm{pH}$ inferior a 6.
Gama et al. (2004) analisaram a água de dessedentação de aves de postura no município de Bastos (SP), e os resultados indicaram que $45,0 \%$ das águas provenientes de poço apresentaram-se com o pH inferior a 6. Ressalta-se que na região em questão incide a maior concentração de galinhas destinadas à produção de ovos no Brasil.

$\mathrm{Na}$ dureza, em 94,1\% das granjas encontraram-se adequação com o Ofício Circular Conjunto DFIP/DSA nº 1/2008 de acordo com o número de aves, conforme apresentado na Tabela 2. Este percentual aumenta um pouco $(95,7 \%) \mathrm{em}$ relação à dureza de acordo com o tipo de fonte (Tabela 3). Segundo Vohra (1980), a dureza da água é um parâmetro que não é prejudicial às aves, a não ser que ela esteja presente em quantidades tóxicas. Especula-se que a dureza pode estar relacionada com o surgimento da síndrome do fígado graxo em poedeiras, embora Jensen et al. (1977) não tenham conseguido êxito em demonstrar esta relação experimentalmente. Para LAgger et al. (2000), a dureza pode interferir na qualidade microbiológica da água, pela falta de

Tabela 2. Qualidade da água de granjas de postura comercial da região Sul de Santa Catarina em adequação aos padrões indicados pelo Ofício Circular Conjunto DFIP/DSA n 1/2008, em relação ao número de aves em produção.

\begin{tabular}{|c|c|c|c|c|c|c|}
\hline \multirow{3}{*}{ Parâmetros } & \multicolumn{2}{|c|}{ Até 20 mil poedeiras } & \multicolumn{2}{|c|}{ Acima de 20 mil poedeiras } & \multirow{3}{*}{ Média } & \multirow{3}{*}{ CV (\%) } \\
\hline & Granjas adequadas & Granjas inadequadas & Granjas adequadas & Granjas inadequadas & & \\
\hline & n (\%) & n (\%) & n (\%) & n (\%) & & \\
\hline SDT & $17(100,00)$ & $0(0,00)$ & $14(100,00)$ & $0(0,00)$ & $78,19 \mathrm{ppm}$ & - \\
\hline $\mathrm{pH}^{*}$ & $14(82,35)$ & $3(17,64)$ & $9(64,29)$ & $5(35,71)$ & $6,45 \mathrm{pH}$ & 11,25 \\
\hline Dureza & $15(88,23)$ & $2(11,77)$ & $14(100,00)$ & $0(0,00)$ & $37,49 \mathrm{mg} / \mathrm{L}$ & - \\
\hline Cloreto* & $17(100,00)$ & $0(0,00)$ & $14(100,00)$ & $0(0,00)$ & $21,32 \mathrm{mg} / \mathrm{L}$ & 35,67 \\
\hline Nitrato* & $9(52,94)$ & $8(47,06)$ & $5(35,71)$ & $9(64,29)$ & $16,14 \mathrm{mg} / \mathrm{L}$ & - \\
\hline Sulfato* & $17(100,00)$ & $0(0,00)$ & $14(100,00)$ & $0(0,00)$ & $4,51 \mathrm{mg} / \mathrm{L}$ & 83,15 \\
\hline E. coli* & $9(52,94)$ & $8(47,06)$ & $8(57,14)$ & $6(42,86)$ & - & - \\
\hline
\end{tabular}

*Não ocorreu diferença estatística conforme o número de aves $(p>0,05)$

Tabela 3. Qualidade da água de granjas de postura comercial da região Sul de Santa Catarina em adequação aos padrões indicados pelo Ofício Circular Conjunto DFIP/DSA n 1/2008, de acordo com a origem da água.

\begin{tabular}{|c|c|c|c|c|c|c|}
\hline \multirow{3}{*}{ Parâmetros } & \multicolumn{2}{|c|}{ Poço } & \multicolumn{2}{|c|}{ Vertente } & \multirow{3}{*}{ Média } & \multirow{3}{*}{ CV (\%) } \\
\hline & Granjas adequadas & Granjas inadequadas & Granjas adequadas & Granjas inadequadas & & \\
\hline & n (\%) & n (\%) & n (\%) & n (\%) & & \\
\hline SDT & $23(100,00)$ & $0(0,00)$ & $8(100,00)$ & $0(0,00)$ & $72,77 \mathrm{ppm}$ & - \\
\hline $\mathrm{pH}^{*}$ & $16(69,60)$ & $7(30,40)$ & $7(87,50)$ & $1(12,50)$ & $6,5 \mathrm{pH}$ & 11,81 \\
\hline Dureza & $21(91,30)$ & $2(8,70)$ & $8(100,00)$ & $0(0,00)$ & $33,53 \mathrm{mg} / \mathrm{L}$ & - \\
\hline Cloreto* & $23(100,00)$ & $0(0,00)$ & $8(100,00)$ & $0(0,00)$ & $21,6 \mathrm{mg} / \mathrm{L}$ & 35,64 \\
\hline Nitrato* & $10(43,48)$ & $13(56,52)$ & $4(50,00)$ & $4(50,00)$ & $15,74 \mathrm{mg} / \mathrm{L}$ & - \\
\hline Sulfato* & $23(100,00)$ & $0(0,00)$ & $8(100,00)$ & $0(0,00)$ & $4,26 \mathrm{mg} / \mathrm{L}$ & 83,4 \\
\hline E. coli* & $15(65,20)$ & $8(34,80)$ & $2(25,00)$ & $6(75,00)$ & - & - \\
\hline
\end{tabular}

*Não ocorreu diferença estatística conforme o tipo de fonte $(p>0,05)$. 
eficiência dos detergentes na higienizaçáo dos equipamentos, quando ultrapassa $100 \mathrm{mg} / \mathrm{L}$ de $\mathrm{CaCO}_{3}$. A água com dureza elevada indica que existe alta concentraçáo de cálcio e magnésio em solução, podendo ter sabor desagradável e levar a uma diminuição do consumo de água pela ave, o que influenciará diretamente sobre a produçáo. Outro problema é o efeito laxativo que a dureza propicia nas aves e, também, a formação de biofilme nas tubulaçôes (GAMA et al., 2004; FAIRCHILD; Ritz, 2006).

Todas as amostras apresentaram-se adequadas para níveis de cloreto, o que significa que em nenhuma granja a água ultrapassou a concentraçáo de $250 \mathrm{mg} / \mathrm{L}$ (Tabela 1). Elevadas concentraçóes de cloretos podem conferir sabor salgado à água. Tal situação pode ser decorrente de infiltração de águas residuárias, urina de pessoas e animais (MOUCHreK, 2003).

Furlan et al. (1999) estudaram o efeito da cloração da água de beber sobre o consumo e ganho de peso em frangos de corte, e os resultados apontaram para o menor consumo de água quando clorada, embora sem influenciar o ganho de peso das aves.

Do total das amostras analisadas, 54,8\% estavam inadequadas para o nível de nitrato (Tabela 1). Os resultados das análises de nitrato, de acordo com o número de aves, tiveram a média de 55,7\% de amostras inadequadas (Tabela 2), enquanto conforme o tipo de fonte que abastece as granjas a inadequação foi de 53,3\% (Tabela 3). Todas as granjas inadequadas apresentaram a concentração de nitrato nas amostras acima de $10 \mathrm{mg} / \mathrm{L}$. O nitrato em concentraçáo elevada é tóxico para a ave pelo seu efeito sobre o ferro presente na hemoglobina, prejudicando, assim, o transporte do oxigênio para as células (MACÊDo, 2007; Pomiano, 2002). Isso acarreta em prejuízo financeiro para o produtor pelos efeitos adversos dessa toxicidade sobre as aves, como inibição do crescimento, diminuição do apetite e agitação, o que reflete diretamente sobre a produção (ARKHIPOv, 1989).

As principais fontes de poluição por nitrato são, em geral, as lixívias dos adubos de solos de uso agrí́cola e os efluentes das estaçôes de tratamento. $\mathrm{O}$ nitrato pode chegar à água por meio da chuva (EIFAC, 1984). Devido ao alto índice das amostras de água das granjas da regiáo Sul de Santa Catarina estarem $(54,8 \%)$ no quesito nitrato, e devido aos efeitos negativos causados não só à saúde das aves, como também para a saúde humana, entende-se ser interessante uma ação ostensiva do poder público e órgãos fiscalizadores no sentido de corrigir esta situação.

Para os resultados dos níveis de sulfato, todas as amostras apresentaram-se adequadas (Tabela 1), sendo que $83,9 \%$ das concentraçóes encontraram-se na faixa de $0-5 \mathrm{mg} / \mathrm{L}$. Não foi encontrada nenhuma inadequação de sulfato nas amostras analisadas, tanto em relação ao número de aves (Tabela 2) quanto em relação ao tipo de fonte (Tabela 3). No trabalho de Gama et al. (2004), realizado na regiáo de
Bastos (SP), todas as amostras testadas revelaram índices aceitáveis de concentração de sulfato. Esses resultados são positivos, pois a água com alta concentraçấo de sulfato possui odor fétido, potabilidade ruim e açấo laxativa, podendo interferir na absorção intestinal de minerais, como cobre. Níveis abaixo de $50 \mathrm{mg} / \mathrm{L}$ podem exercer um efeito negativo na performance dos lotes, e também se o nível de $\mathrm{Na}$ ou $\mathrm{Mg}$ for maior que $50 \mathrm{mg} / \mathrm{L}$ (Coetzee, 2005).

$\mathrm{Na}$ análise de $E$. coli encontrou-se inadequação em $45,2 \%$ das amostras (Tabela 1). Gama et al. (2004) encontraram $60,0 \%$ das amostras contaminadas por coliformes fecais. Esses resultados revelam que o tratamento da água utilizada na dessedentação das aves de postura não está sendo realizado corretamente. Ramires et al. (2009) também demonstraram alta contaminação por coliformes fecais ao analisarem a qualidade da água de 162 propriedades produtoras de leite em Campos Gerais (PR), observando uma contaminação de $56,7 \%$ por coliformes fecais. Outro estudo mostrou que a contaminação fecal da água é um problema relevante nas propriedades rurais em Jaboticabal (SP), onde aproximadamente metade das propriedades amostradas obteve presença de E. coli confirmada na água da fonte de abastecimento e ponto de consumo humano (SATAKE et al., 2012).

A Tabela 4 apresenta detalhadamente o resultado das análises químicas e microbiológicas em cada granja, assim como o tipo de fonte e número de aves.

Do total geral de todos os parâmetros analisados, 93,5\% das amostras não se enquadraram nas exigências do Ofício Circular Conjunto DFIP/DSA no 1/2008 (Fig. 1). No Reino Unido, verificaram-se que $100 \%$ dos poços e $63 \%$ das nascentes estavam fora dos padrôes microbiológicos de potabilidade humana (Fewtrell; Godfree, 1998). Em propriedades na regiâo Nordeste do estado de São Paulo, verificaram-se que $90 \%$ das amostras de água utilizadas na produçáo de leite estavam fora dos padróes microbiológicos de potabilidade (AMARAL et al., 1995).

A água é uma excelente via de transmissão de enfermidades para humanos e animais, principalmente daquelas que têm a rota e a transmissão fecal-oral, pois cada vez mais as atividades urbanas e rurais contaminam os lençóis de água em nosso meio. A tomada de medidas preventivas, e até de medidas saneadoras de problemas já instalados, deve ser o objetivo de todos (Macari; Soares, 2012).

\section{CONCLUSÃO}

As amostras de água das granjas da regiáo Sul de Santa Catarina apresentam-se adequadas ao Ofício Circular Conjunto DFIP/DSA no 1/2008 nos parâmetros sólidos 
Tabela 4. Resultados das análises realizadas em cada granja.

\begin{tabular}{|c|c|c|c|c|c|c|c|c|c|}
\hline Granjas & $\mathrm{pH}$ & $\begin{array}{c}\text { Cloreto } \\
\mathrm{mg} / \mathrm{L}\end{array}$ & $\begin{array}{c}\text { Dureza } \\
\text { mg/L }\end{array}$ & $\begin{array}{c}\text { Nitrato } \\
\mathrm{mg} / \mathrm{L}\end{array}$ & $\begin{array}{c}\text { Sulfato } \\
\mathrm{mg} / \mathrm{L}\end{array}$ & SDT ppm & $\begin{array}{c}\text { E.coli } \\
\text { NMP/100 mL }\end{array}$ & Fonte & $\begin{array}{c}\text { Número de } \\
\text { aves }\end{array}$ \\
\hline 1 & 5,5 & 20 & 10 & 24 & 5 & 75,6 & $>1100$ & Poço & 40.000 \\
\hline 2 & 6,2 & 18 & 8 & 10 & 5 & 44,8 & 93 & Poço & 40.000 \\
\hline 3 & 5,4 & 10 & 8 & 25 & 5 & 40,5 & 0 & Poço & 6.000 \\
\hline 4 & 6,2 & 20 & 20 & 10 & 5 & 51,8 & 0 & Poço & 1.400 \\
\hline 5 & 5,5 & 20 & 20 & 23 & 5 & 50,8 & 0 & Poço & 25.000 \\
\hline 6 & 6,3 & 20 & 40 & 20 & 5 & 70,6 & 460 & Poço & 3.000 \\
\hline 7 & 5,5 & 22 & 22 & 24 & 5 & 90,8 & 0 & Poço & 3.000 \\
\hline 8 & 7,6 & 40 & 62 & 24 & 10 & 157 & 0 & Poço & 13.000 \\
\hline 9 & 6,1 & 18 & 18 & 24 & 5 & 55 & 1100 & Poço & 30.000 \\
\hline 10 & 6,5 & 20 & 20 & 9 & 5 & 58,8 & 240 & Poço & 25.000 \\
\hline 11 & 6,6 & 20 & 70 & 3 & 5 & 124 & 0 & Poço & 30.000 \\
\hline 12 & 7,1 & 30 & 30 & 22 & 5 & 85,6 & 0 & Poço & 20.000 \\
\hline 13 & 5,4 & 18 & 50 & 24 & 5 & 48,9 & 0 & Poço & 20.000 \\
\hline 14 & 7,5 & 20 & 38 & 9 & 5 & 67,7 & 15 & Poço & 17.000 \\
\hline 15 & 5,3 & 20 & 38 & 22 & 5 & 75,6 & 0 & Poço & 22.000 \\
\hline 16 & 8,2 & 38 & 200 & 0 & 10 & 282 & 0 & Poço & 2.000 \\
\hline 17 & 7,5 & 20 & 170 & 3 & 15 & 248 & 0 & Poço & 8.000 \\
\hline 18 & 6,6 & 10 & 8 & 7 & 5 & 27 & 9,1 & Poço & 5.217 \\
\hline 19 & 6,7 & 20 & 30 & 25 & 5 & 54,1 & 0 & Poço & 4.000 \\
\hline 20 & 6,8 & 20 & 15 & 10 & 5 & 39 & $>1100$ & Poço & 4.900 \\
\hline 21 & 5,5 & 20 & 25 & 25 & 5 & 77,9 & 0 & Poço & 28.000 \\
\hline 22 & 6,2 & 18 & 50 & 25 & 5 & 93,4 & 0 & Poço & 34.000 \\
\hline 23 & 7,6 & 20 & 50 & 6 & 5 & 64,4 & 0 & Poço & 17.000 \\
\hline 24 & 7,2 & 28 & 20 & 23 & 5 & 36,4 & 9,4 & Vertente & 28.000 \\
\hline 25 & 6,5 & 18 & 20 & 25 & 10 & 54,9 & 1100 & Vertente & 10.000 \\
\hline 26 & 7,5 & 15 & 30 & 10 & 10 & 77,4 & 0 & Vertente & 10.000 \\
\hline 27 & 7,1 & 10 & 25 & 24 & 5 & 58,9 & 11 & Vertente & 25.000 \\
\hline 28 & 5,4 & 40 & 38 & 25 & 5 & 92,9 & 9,1 & Vertente & 3.000 \\
\hline 29 & 6,5 & 20 & 25 & 2 & 5 & 47,7 & 14 & Vertente & 3.000 \\
\hline 30 & 6,1 & 30 & 20 & 10 & 5 & 70,9 & 0 & Vertente & 25.000 \\
\hline 31 & 7,2 & 18 & 10 & 3 & 5 & 35,4 & 12 & Vertente & 35.000 \\
\hline
\end{tabular}

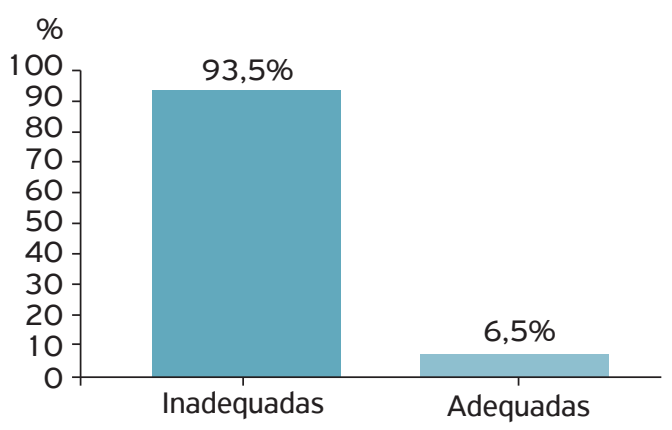

Figura 1. Adequação geral das amostras analisadas ao Ofício Circular Conjunto DFIP/DSA nº 1/2008 dissolvidos totais, cloreto e sulfato. No entanto, apresentam inadequaçóes no que se refere a pH (26\%), dureza (6,4\%), nitrato (54,8\%) e Escherichia coli (45,2\%). A qualidade da água independe do número de aves em produçáo e do tipo de fonte que abastece a granja.

\section{AGRADECIMENTOS}

Agradecemos aos produtores que colaboraram para a realização deste estudo, sendo que eles receberam laudos com os resultados das análises para as devidas adequaçóes. 


\section{REFERÊNCIAS}

AMARAL, L.A.; NADER FILHO, A.; ROSSI JR, O.D., PENHA, L.H.C. Características microbiológicas da água utilizada no processo de obtenção do leite. Pesquisa Veterinária Brasileira, v. 15, n.2/3, p.85-88, 1995.

ARKHIPOV, A. Nitrates and nitrites in feeds. Ptitsevodstvo. Moscow, v.7, p.31-33, 1989.

BLOCK, S.S. Disinfection, sterilization and prevention. 4. ed. Philadelfia: Lea e Febiger, 1991. 1.162p.

BRASIL. Ministério da Agricultura, Pecuária e Abastecimento. Instrução Normativa n 56, de 4/12/2007. Estabelece os procedimentos para registro, fiscalização e controle de estabelecimentos avícolas de produção e comerciais. Diário Oficial da União. Brasília, 2007.

CARTER, T.A.; SNEED, R.E. Drinking water quality for poultry. Raleigh: North Carolina Cooperative Extension Poultry Science. 1996. (Publication number: PS\&T Guide n42).

COETZEE, C.B. The development of water quality guidelines for poultry production in southern Africa. 2005. 195p. Tese (Doutorado em Animal Science) - Faculty of Natural and Agricultural Sciences, University of Pretoria, Pretoria, 2005.

DA SILVA, N.; CANTÚSIO NETO, R.; JUNQUEIRA, V.C.A.; SILVEIRA, N.F.A. Manual de métodos de análise da água. São Paulo: Livraria Varela. 2005.

EUROPEAN INLAND FISHERIES ADVISORY COMMISION - EIFAC. Technical paper 46/1984: Water quality criteria for European freshwater fish. Report on nitrite and freshwater fish, FAO, Roma. 1984.

FAIRCHILD, B.D.; RITZ, C.W. Poultry drinking water primer. Bulletin 1301, The University of Georgia and Ft. Valley State University, the U.S. Department of Agriculture and counties of the state cooperating, abril, 2006.

FEWTRELL, L.; KAY, D.; GODFREE, A. The microbiological quality of private water supplies. Journal Ciwen, v.12, p.98-100, 1998.

FIGUEIREDO, R.M. Programa de redução de patógenos. São Paulo: Câmara Brasileira do Livro, 1999. $81 \mathrm{p}$.

FURLAN, R.L.; MACARI, M.; MALHEIROS, E.B.; INGRACI, C.; MEIRELES, H.T. Efeito da cloração da água de beber e do nível energético da ração sobre o ganho de peso e consumo de água em frangos de corte. Revista Brasileira de Zootecnia, v.28, n.3, p.542-547, 1999.

GAMA, N.M.S.Q.; GUASTALLI, E.A.L.; AMARAL, L.A.; FREITAS, E.R.; PAULILLO, A.C. Parâmetros químicos e Indicadores bacteriológicos da água utilizada na dessedentação de aves nas granjas de postura comercial. Arquivos do Instituto Biológico, São Paulo. v.71, n.4, p.423-430, 2004.

GEWEHR, C.E.; STAHLHOFER, S.R.; RITTER, G.S.; DA SILVA, M.C. Cadeia produtiva de ovos comerciais de Santa Catarina: perfil dos produtores e das propriedades. Revista de Ciências Agroveterinária. Lages, v.9, n. 1, p.90-98, 2010.
JENSEN, L.; MAURICE, D.V.; CHANGE, C.H. Relationship of mineral content of drinking water to lever lipid accumulation in laying hens. Poultry Science, v.56, p.260-266, 1977.

LAGGER, J.R.; MATA, H.T.; PECHIN, G.H.; LARREA, A.T.; OTROSKY, R.N.; CESAN, R.O.; CAIMIER, A.G.; MEGLIA, G.E. La importancia de la calidad del agua en producción lechera. Veterinaria Argentina. v.27, n.165, p.346-354, 2000.

LAURENTIZ, A.C.; SILVA-FILARDI; P.P.; SERRANO SUGETA, S.M.; MAIORKA, A. Utilização de ácido acético via água de bebida durante a primeira semana em frangos de corte. Revista Brasileira Ciência Avícola, v.3, supl.3, p.23, 2001.

MACARI, M.; SOARES, N.M. Água na Avicultura Industrial. São Paulo: Fundação Apinco de Ciência e Tecnologia Avícolas, 2012. 359p.

MACÊDO, J.A.B. Águas $\diamond$ águas. Belo Horizonte: CRQ-MG. 2007. 977p.

MOUCHREK, E. Qualidade da água. Revista AVIMIG, v.4, n.34, p.14-15, 2003.

NATIONAL RESEARCH COUNCIL - NRC. 1974. Nutrients and toxic substances in water for livestock and poultry. Washington, DC: National Academy of Science.

PENZ JUNIOR, A.M.A importância da água como nutriente na produção de frangos de corte. In: CONFERÊNCIA APINCO 2002 DE CIÊNCIA DE TECNOLOGIA AVÍCOLAS. Anais... Santos: FACTA, 2002. p.63-80.

POMIANO, J.D. Manejo del agua como nutriente. Lima. 2002. p. 1-31.

RAMIRES, C.H.; BERGER, E.L.; ALMEIDA, R. Influência da qualidade microbiológica da água sobre a qualidade do leite. Archives of Veterinary Science, v.14, n. 1, p.36-42, 2009.

SAS INSTITUTE. SAS/STAT User's Guide 8.0. Cary-NC: SAS Institute. 1999.

SATAKE, F.M.; ASSUNÇÃO, A.W.A.; LOPES, L.G.; AMARAL, L.A. Qualidade da água em propriedades rurais situadas na bacia hidrográfica do córrego rico, Jaboticabal, SP. Ars veterinaria, v.28, n. 1, p.48-55, 2012.

SOARES, N.M.; MESA, D.A. Manejo da água na produção de ovos. 2009. Artigo em hypertexto. Disponível em: <http://www. infobibos.com/Artigos/2009_3/ovos/index.htm>. Acesso em: 18 nov. 2012.

TABLER, G.T. Water intake: a good measure of broiler performance. Avian Advise, v.5, n.3, p.7-9, 2003.

THULIN, A.J.; BRUMM, M.C. Water: The forgotten nutrient. In: MILLER, E.R.; ULLREY, D.E.; LEWIS, A.J.(Ed.). Swine nutrition. Woburn: Butterworth-Heinemann. p.315-324. 1991.

VOHRA, N.P. Water quality for poultry use. Feedstuffs, v.7, p.24-25, 1980. 